\title{
EL PLACER DE LA COMPLEJIDAD EN EL LENGUAJE PICTÓRICO. EJEMPLOS EN UNA CLASE DE PINTURA
}

\author{
Sabina Gau Pudelko \\ Universidad de La Laguna \\ sagako@ull.edu.es
}

\section{RESUMEN}

Desde un enfoque académico se estudia la complejidad del pensamiento visual a partir de la descripción resumida de cinco tipos de contenido que se han asociado a la producción artística. Se han analizado por separado en los epígrafes titulados Narrar algo interesante; Generar belleza; Desarrollar la capacidad creadora; Transmitir un contenido sensible, emotivo o sentimental; y Jugar con el lenguaje. En cada uno de estos apartados se puede alcanzar un alto grado de matización, pero es la confluencia de varios de ellos en una misma imagen lo que da fe de la complejidad del pensamiento visual que puede ejercitarse y desarrollarse mediante la práctica de la pintura. Para ejemplificar algunos aspectos de esta reflexión se han incorporado imágenes realizadas por estudiantes de Bellas Artes. Suelen proceder de las memorias no publicadas que se elaboran en asignaturas de pintura. Se trata, en resumen, de una reflexión sobre la complejidad asociada al pensamiento visual que puede localizarse en imágenes pintadas, quedando patentes, también, los límites del análisis racional para abarcarla por completo.

Palabras Clave: arte, psicología, pensamiento visual, pintura, complejidad, enseñanza.

THE PLEASURE OF COMPLEXITY IN PICTORIAL LANGUAGE.

EXAMPLES IN A PAINTING CLASS

\section{Abstract}

From an academic approach the complexity of visual thinking is studied from the summary description of five types of content that have been associated with artistic production. They have been analyzed separately in the headings entitled: Narrate something interesting; Generate beauty; Develop creative capacity; Transmit a sensitive, emotional or sentimental content; Play with the language. In each of these sections a high degree of qualification can be achieved, but it is the confluence of several of them in the same image that attests to the complexity of visual thinking that can be exercised and developed through the practice of painting. To exemplify some aspects in this article, images made by students of fine arts have been incorporated. They usually come from unpublished reports that are made in painting subjects. It is, in summary, a reflection on the complexity associated with visual thinking that can be found in painted images, and the limits of rational analysis are also evident to cover it completely.

KeYwOrds: Art, psychology, visual thinking, painting, complexity, teaching.

DOI: https://doi.org/10.25145/j.bartes.2019-20.14.04

Revista Bellas Artes, 14; abril 2017-18, pp. 69-89; ISSN: e-2530-8432 
En este artículo se pretende analizar la complejidad de la imagen pictórica. Para ello se repasan someramente diferentes contenidos que se han atribuido al arte y que, en gran parte, tienen su origen en el pensamiento visual. Estos contenidos se superponen en diferentes niveles de significación y compete al artista intentar alcanzar una armonización satisfactoria. Como profesora de pintura me he preguntado el porqué de la pintura. Puedo imaginar el placer de un nińo que marca una pared limpia con una mano llena de barro, pero ahora se trata de buscar las motivaciones que inducen a un adulto a pintar un cuadro o a mirar imágenes pintadas. Se pinta como se piensa y siente, e intentaré referirme a diferentes tipos de pensamiento que pueden ser legibles por medio de la pintura, sin pretender agotarlos.

Algunas personas se interesan en primer lugar por los mensajes que las imágenes pueden transmitir, quieren narrar algo interesante. Por deformación profesional, ese es el tipo de contenidos a los que prestaré menos atención, pero sólo porque pienso que son más fáciles de comprender al depender de aspectos culturales, en ocasiones, circunstanciales. También se ha atribuido a las artes la función de generar belleza. Esta asociación quizás sea más fácil de encontrar entre las personas aficionadas al arte que entre las que lo producen. Desarrollar la capacidad creadora es, desde hace décadas, otra de las tareas que se encomiendan a la educación artística. Es cierto que en la producción artística se encuentra la clase de pensamiento diferenciado por etapas que se atribuye a un proceso de creación. Más difícil de comprender es la capacidad de las artes de transmitir emociones, aunque, a mi juicio, es una de sus funciones más importantes, pues las artes codifican sensaciones que nos llegan de todos nuestros sentidos, no sólo de la visión. Los estudiantes de arte suelen referirse a esta capacidad con frecuencia y fuera de las artes me resulta difícil encontrar esa codificación. Finalmente, me referiré al juego con el lenguaje que tal vez implique la interacción de algunos de los puntos anteriores y que considero uno de los motores de la actividad artística.

He observado que los estudiantes de Bellas Artes comparten las mismas motivaciones que los pintores profesionales. He ejemplificado algunas de mis reflexiones sobre sus trabajos, que han sido pintados, salvo una excepción, en dos asignaturas de segundo curso del grado en Bellas Artes. Quiero agradecer a mis alumnos sus discusiones y su confianza.

\section{NARRAR ALGO INTERESANTE}

Los humanos sentimos necesidad de construir ficciones. Un relato permite construir una arquitectura contextual que admite la incorporación de nueva información y su confrontación con aquella que ya conocemos. La interacción de esta información -racional, objetiva o fantasiosa- alienta la construcción de otras hipótesis posibles y nos permite avanzar en el aprendizaje. También se pueden narrar contenidos ya conocidos bajo enfoques nuevos o en lenguajes distintos. Las artes plásticas tienen un potencial menor para narrar que aquellas que tienen una dimensión temporal como las literarias, el cine o la danza, pues suelen mostrar su contenido 
en tiempo presente; pero pueden representar y evocar relatos ya sabidos en virtud de una serie de signos, símbolos o rasgos pertinentes.

Algunos alumnos empiezan a estudiar pintura porque quieren aprender a comunicar mensajes mediante imágenes. Para algunos muralistas este aspecto es el más importante. Ya sabemos que el carácter analógico del código pictórico, unido a un alto grado de iconicidad, permite representar objetos, figuras y ambientes en contextos determinados. Por su parte, los estudios históricos o iconográficos pueden añadir complejidad a la interpretación de su significado. Así, el estudio de los elementos de una figura de contenido religioso, por ejemplo, puede hacernos ver su instrumentalización política y bélica o indagar en los significados sincréticos que ha ido importando a través del tiempo ${ }^{1}$. Hay que decir, sin embargo, que a pesar del indudable interés de este tipo de interpretaciones, no suelen decidir la calidad artística de un cuadro. Esta se encontrará, en muchas ocasiones, en aspectos formales, construidos con más o menos sensibilidad, y que podrán sumar otros contenidos a los iconográficos. Pero es indudable, también, que un contenido metafórico inteligente añade interés a un buen cuadro y que, además, ese contenido probablemente originó su ideación. Podríamos fijarnos, por ejemplo, en una famosa serie de pinturas que el pintor Anselm Kiefer tituló Böhmen liegt am Meer [Bohemia está junto al mar] (1995) (https:/www.museum-frieder-burda.de/de/museum/sammlung/deutschekunst-nach-1960/kuenstler/anselm-kiefer/, consulta el 03/07/2019). El autor se basa en un poema de Ingeborg Bachmann que trata sobre el anhelo de la utopía, que por definición nunca se alcanza. Esta idea se transmite a través del título escrito sobre el lienzo, ya que el territorio de la antigua Bohemia se encuentra en el centro de Europa, sin salida al mar. El pintor lo representa con la imagen de un lejano horizonte al que se dirige un camino. En una composición simétrica, aparentemente simple, se conjugan el cruce de varias direcciones, contrastes de texturas, profusión de materiales diferentes y la oposición entre la imagen y la escritura. Esta última aporta el significado metafórico. En diferentes imágenes sobre el mismo tema se añade una impresión ambiental inquietante o placentera. Las grandes dimensiones de las obras permiten al espectador sentirse dentro del paisaje. En este caso nos encontramos ante un cuadro rico desde el punto de vista formal y semántico.

En su trabajo de fin de grado nuestra alumna Federica Furbelli se propuso reivindicar las emociones y la naturaleza primitiva frente a la homogeneización de un mundo cada vez más occidentalizado donde impera el racionalismo. Para ello elaboró una serie de cuadros sobre una exuberante vegetación tropical en una combinación dinámica y alegre. Una alusión clara al paisaje exótico de Indonesia se encuentra, en este caso, en los títulos de los cuadros (figura 1).

${ }^{1}$ Un estudio iconográfico de este tipo se encuentra en Miguel Ángel Martín Sánchez, Miguel, el arcángel de Dios en Canarias. Aspectos socioculturales y artísticos (Santa Cruz de Tenerife: Cabildo Insular de Tenerife, 1991). 


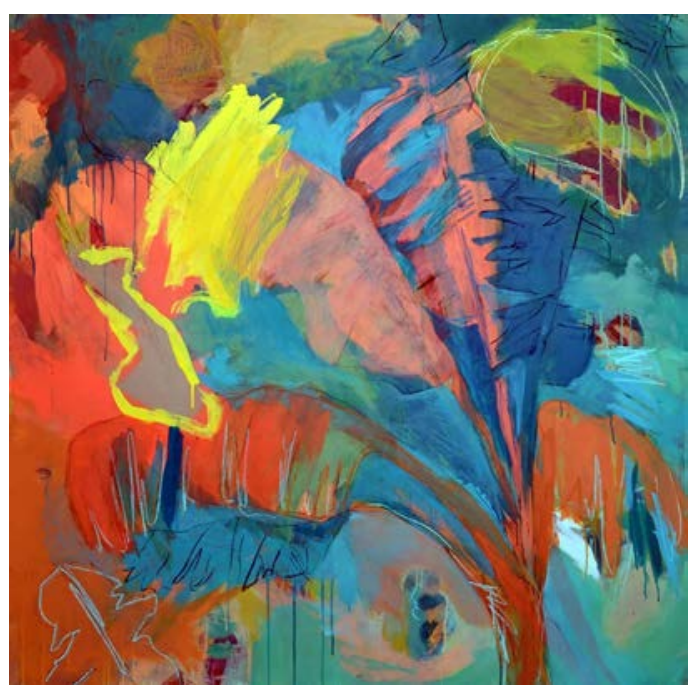

Fig. 1. Federica Furbelli, Surga hilang, acrílico, cera y espray sobre tabla, $122 \times 122$ cm, 2018 .

\section{GENERAR BELLEZA}

La belleza ha estado mucho tiempo ligada al concepto de arte. El físico Frank Wilczek relaciona la belleza con la simetría y la economía de medios ${ }^{2}$ que se encuentra en el diseño profundo de las formas naturales. También los psicólogos de la Gestalt encontraron en la claridad de la simetría una de las condiciones de una buena Gestalt, que favorece la percepción.

El conocimiento de los distintos tipos de simetría, y su interrelación, también ayuda a comprender la estructura de muchas configuraciones aparentemente complejas ${ }^{3}$, aspecto esencial para aprender a dibujar. Tradicionalmente, las leyes de la composición pictórica hacían referencia tanto a la simetría como también al equilibrio, la proporción y el ritmo, que aparecen en la primera. Estos cuatro conceptos ${ }^{4}$ tienen mucho que ver con la economía de esfuerzos y de medios (figura 2). El tipo de sensación que genera una obra basada en la simetría, la proporción y el equilibrio es bastante agradable por su estabilidad y su grado adecuado de previsibilidad. Es el tipo de estructuras que pueden encontrarse en los cuadros de periodos clási-

${ }^{2}$ Frank Wilczek, El mundo como obra de arte. En busca del diseño profundo de la naturaleza (Barcelona: Crítica, 2015).

${ }^{3}$ La obra pictórica de Gilbert \& George podría ser un ejemplo.

${ }^{4}$ Pilar Blanco y Sabina Gau, Fundamentos de la composición pictórica (Santa Cruz de Tenerife: Consejería de Educación, Cultura y Deportes, Dirección General de Universidades e investigación, Gobierno de Canarias, 1996). 


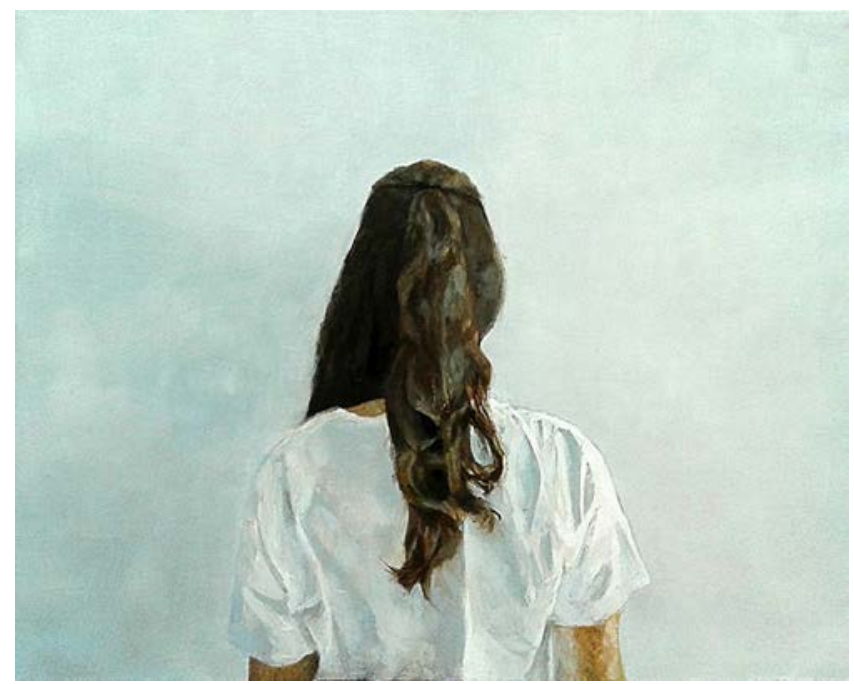

Fig. 2. Irene Morales Almeda, Sin titulo, óleo sobre lienzo, $65 \times 81 \mathrm{~cm}, 2017$.

cos como Los desposorios de la Virgen, de Rafael. A veces se aprecia como bella una obra con un orden menos claro, aunque su estructura se asiente en relaciones simétricas y diferentes tipos de proporción, sobre todo la sección áurea, tan presente en el crecimiento de los seres vivos. Pero, a mi juicio, el placer estético implica muchos otros aspectos además de la relajada percepción del equilibrio y la regularidad. Esto tiene que ver con el contenido emotivo que es capaz de transmitir una imagen y que depende también de otros factores, como nuestra memoria filogenética y la complejidad en el uso del lenguaje. Así, en el caso de la pintura, podría entenderse como bella una sofisticada armonía cromática o una sutil matización de la luz. Ello explica que la aparente sencillez de una obra de Morandi no sea simple en absoluto, ya que da fe de una fina sensibilidad en la que el artista ha podido profundizar gracias al ejercicio de la pintura.

En cuanto a aquellos aspectos formales que suelen apreciarse como bellos porque favorecen nuestra supervivencia, y que heredamos con nuestra memoria filogenética, podemos nombrar algunos ejemplos. Aplicado a la reproducción, se suele apreciar como bella la cintura estrecha de una mujer -señal de que conserva intacto todo el potencial reproductor-, también la regularidad de un rostro, el cabello abundante o unos dientes blancos darían fe de una buena salud. Un cuerpo asimétrico o viejo puede indicar lo contrario y resultar feo. También suele resultar bello un hábitat benevolente, como la pradera, con la biomasa accesible y de fácil supervisión ${ }^{5}$.

\footnotetext{
Steven Pinker, Cómo funciona la mente (Barcelona: Destino, 2000), 618-621.
} 
Trasladar sus rasgos formales característicos a un lienzo -incluso en una combinación abstraída- puede generar placer estético, resultar bello. Cabría referirse también a los cánones de belleza que establecen los rasgos distintivos entre personas de diferentes culturas, o a las modas que se generan dentro de un mismo grupo. Pero estas últimas pueden ser variables y más circunstanciales que esenciales.

\section{DESARROLLAR LA CAPACIDAD CREADORA}

La creación se ha asociado al artista por su capacidad de generar imágenes. En el pasado era frecuente aprender por imitación de otros artistas hasta que en el siglo XVI se llega a pensar que la inspiración hace ver al artista cosas vedadas a otras personas. Conocemos imágenes donde se representan musas, espíritus santos o ángeles insuflando ideas a los artistas ${ }^{6}$. Durante la Ilustración el genio se considera máximo exponente del hombre creador y en la época contemporánea la capacidad creadora pierde su asociación con lo divino para pasar a considerarse una importante facultad humana, no sólo ligada a los artistas ${ }^{7}$. Pero es en los años cincuenta del siglo xx, tras la sorpresa que supuso el éxito del primer satélite $S p u t n i k^{8}$, cuando se impulsa en Occidente su estudio sistemático bajo el término de creatividad (Guilford, 1968). Se difunde el interés por la personalidad de los creadores, las fases propias de su pensamiento, los factores que lo caracterizan, así como los métodos que supuestamente lo incentivan. La meta es la producción de ideas originales que faciliten la adaptación a un mundo progresivamente cambiante. En la enseñanza artística suele estar presente como objetivo en los programas docentes?.

Si recordamos las fases del pensamiento creador que encontramos en casi todos los tratados sobre creatividad, veremos que consta de varias etapas: planteamiento de un problema, búsqueda de información, fase de incubación, iluminación o hallazgo de una solución -a veces provisional-, una fase de elaboración y verificación y, por último, la comunicación del resultado ${ }^{10}$. Aunque las fases pueden no desarrollarse siempre en ese orden, sí sabemos que el pensamiento comprometido en un proceso de creación artística es cualitativamente diferente durante su desarrollo. Suele arrancar con el planteamiento de un problema que, en el caso de la pintura, significa visualizar algo que se intenta aclarar, experimentar y comunicar o, dicho ningh, 1980), 160.

${ }^{6}$ Un ejemplo podría ser el cuadro de Jan Gossaert San Lucas pintando a la virgen (1520).

7 Verena Krieger, Was ist ein Künstler? (Colonia: Deubner Verlag, 2007), 115-127.

${ }^{8}$ Klaus Eid et al., Grundlagen des Kunstunterrichts (Paderborn: Verlag Ferdinand Schö-

9 En el ámbito de la enseñanza de la pintura contamos con un texto muy visual y argumentado donde se describen, paso a paso, procesos de creación pictórica: José Luis Tolosa, Mirar haciendo, hacer creando: Práctica y teoría de la pintura (Tres Cantos-Madrid-: Thursen/Hermann Blume, 2005).

${ }_{10}$ Asociada a la pintura contamos con una obra de Günter Regel que trata la producción y recepción de obras de arte y contiene aportaciones de artistas consultados. Günter Regel, Medium bildende Kunst: bildnerischer Prozess und Sprache der Formen und Farben. (Ost-Berlin: Henschelverlag, 1986). 
de otra manera, convertir en imagen una idea o una emoción. En el primer caso, puede tratarse de acotar el enfoque de una temática ${ }^{11} \mathrm{y}$, en el segundo, de expresar un sentimiento que afecta al pintor.

Se ha especulado mucho sobre la inspiración. Puede perfectamente referirse a la fase de iluminación, cuando se vislumbra de manera intuitiva, y no muy clara, un posible proyecto de imagen que pueda canalizar la emoción o idea que pugna por lograr su expresión. Este momento suele ocurrir cuando, de manera más o menos consciente, la información -en este caso sobre todo visual- de la que dispone el autor se articula de manera diferente a la habitual. Esta fase a veces se vive con intensidad emotiva, euforia o desesperación. Se vislumbra la imagen que no existe todavía, ha de ser creada, y arranca una actividad intensa en pos de su exploración. Muchas veces el proceso arranca cuando el pintor se siente afectado por la visión de un objeto o ambiente ${ }^{12}$, otras veces surge en medio de la ejecución de una imagen.

Para el desarrollo de la capacidad creadora, teniendo en cuenta las diferentes fases de su pensamiento, se considera útil programar ejercicios que planteen problemas concretos. Así, por ejemplo, en mis clases de composición suelo pedir a mis alumnos como primer trabajo la armonización de un díptico, aplicando algunas de las leyes gestálticas. Se trata de un planteamiento más lúdico que normativo y se orienta a resolver un problema que admite muchas soluciones diferentes. De esta manera cada alumno podrá experimentar con su propia solución. Pintar el díptico también requiere una capacitación técnica que tendrá que aprender para la ocasión. La puesta en común de los resultados ante toda la clase, para comentar todas las soluciones, a su vez ayuda a flexibilizar las respuestas, pues los estudiantes aprenden recursos de sus compañeros.

Los ejercicios de mímesis, como podría ser la copia de un modelo vivo, se orientan más a aprender los recursos formales de la representación que al desarrollo de la capacidad creadora. Aquí, profesor y alumno aspiran a alcanzar el mismo resultado: la representación en un soporte bidimensional de una escena tridimensional. Estos ejercicios ayudan a discernir las cualidades representables sin los equívocos que a veces conlleva el hecho de que el alumno y el profesor tengan distintas soluciones en mente. Aun así, las preferencias personales de cada estudiante le llevan a una interpretación diferente a la de sus compañeros. Intuitivamente selecciona rasgos, colores o grados de contraste y, con el tiempo y un mayor dominio del lenguaje, predominarán aquellos con los que se identifica más y desaparecerán otros de sus lienzos.

11 Puede incluir un enfoque novedoso, como el cuadro de Las Meninas, de Velázquez, que, en esencia, es un retrato al revés.

${ }^{12}$ Como dice el pintor Antonio López en una entrevista con Soledad Alameda: «Hay algo fundamental para todos, y es que lo que te hace pintar es la emoción. Y esa emoción tiene que salir de una manera u otra si el cuadro está medianamente conseguido [...]. Hay en él una emoción indistinta: lo mismo da que esté expresada con formas figurativas o abstractas, yo no veo diferencia alguna. Ese chispazo que te mueve a empezar un cuadro es lo primordial...». Soledad Alameda, "Antonio López, el que sueña con la luz», El País Semanal 104 (1992): 53-57. 

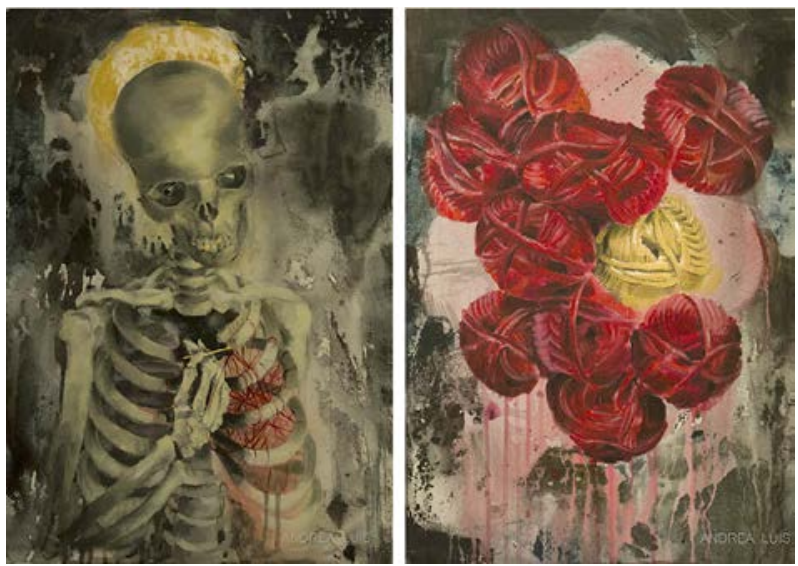

Fig. 3. Andrea Luis Hernández, Red, acrílico sobre lienzo, díptico, $61 \times 50 \mathrm{~cm} \mathrm{c/u,} 2017$.

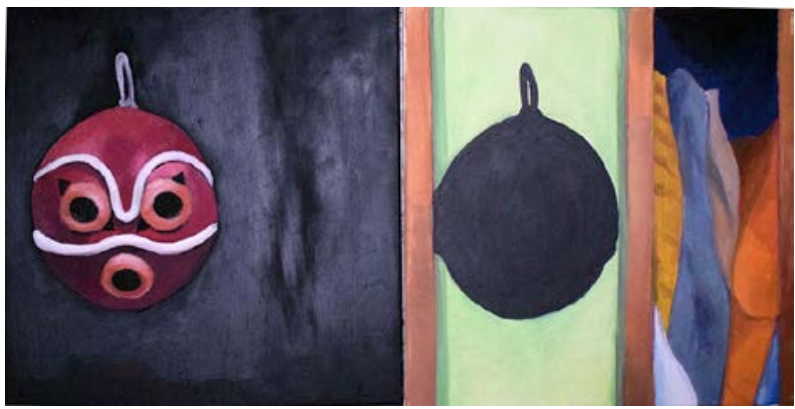

Fig. 4. Briseida Hernández Delgado, Sin título, óleo sobre lienzo, díptico, $40 \times 40$ cm c/u, 2017.
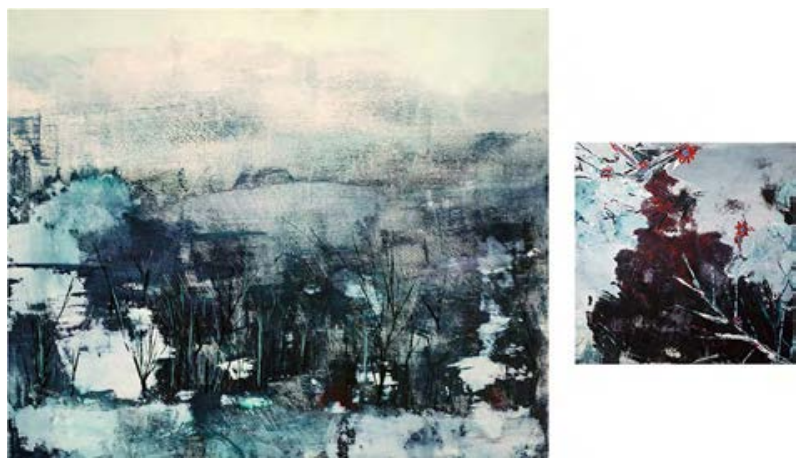

Fig. 5. Elisa García Dorta, Sin título, óleo y acrílico sobre tabla, díptico, $54 \times 65 \mathrm{~cm}$ y $30 \times 30 \mathrm{~cm} 2017$. 


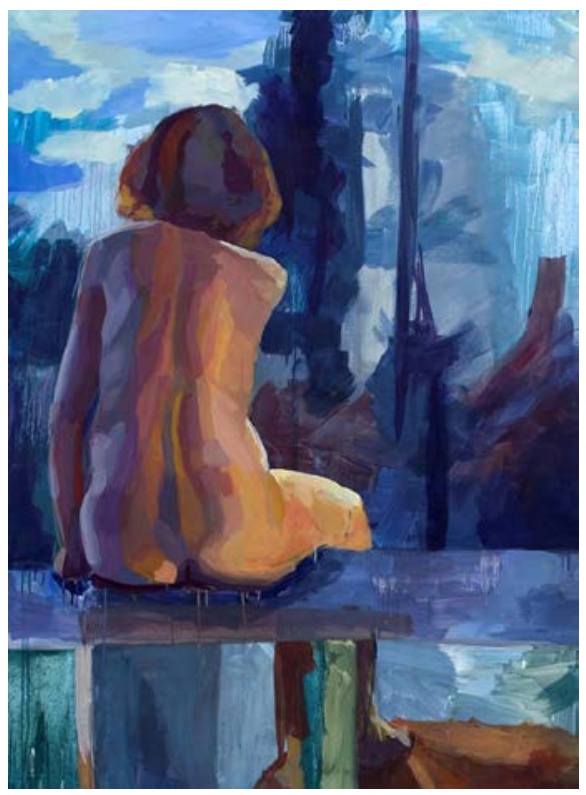

Fig. 6. Sara Vela, óleo, $130 \times 89 \mathrm{~cm}, 2015$.

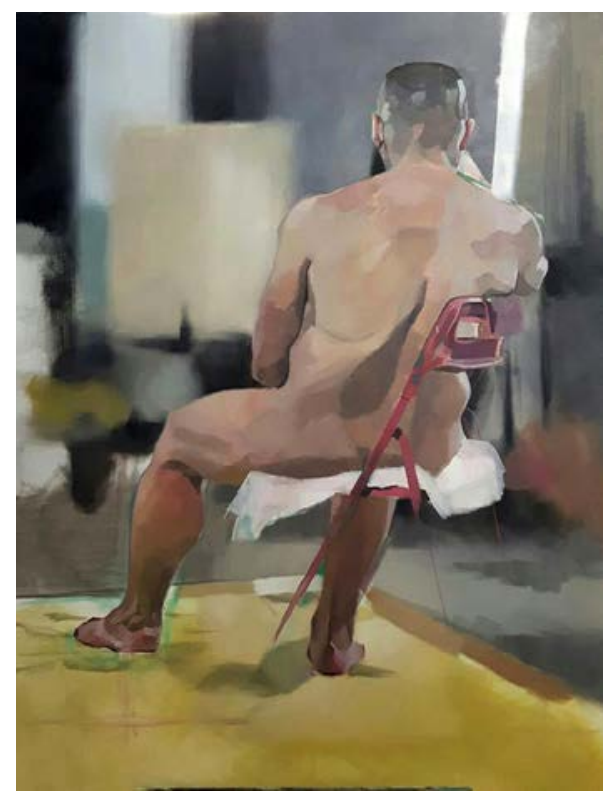

Fig. 7. Marie Sellet Cubillo, óleo, $116 \times 89 \mathrm{~cm}, 2018$.

El problema a resolver no se suele limitar a pintar lo que se ve, tal y como se puede apreciar, sino también, y esto es más difícil de lograr, se trata de que la imagen bien resuelta se adapte a la sensibilidad del autor. Puede suceder que un pintor que domina su lenguaje no encuentre en él los recursos necesarios para expresar un contenido concreto, por lo que tendrá que innovar, y es entonces cuando, en ocasiones, se crean nuevas formas de expresión ${ }^{13}$.

\section{TRANSMITIR UN CONTENIDO SENSIBLE, EMOTIVO O SENTIMENTAL}

Para ejemplificar la influencia de la sensibilidad de un autor en la configuración de una imagen suelo mostrar a mis alumnos dos cuadros de un crucificado muerto, pintado por dos grandes pintores prácticamente coetáneos, sobre el mismo tema y casi con el mismo planteamiento. Diego Velázquez y Pedro Pablo Rubens compartieron época y código pictórico pero su diferente sensibilidad les indujo a

13 En el campo de la pintura sobre la figura humana podríamos citar como ejemplo al pintor Adrian Ghenie. 
pintar de manera distinta. Uno sereno, elegante, comedido en el contraste y centrado en el objeto; el otro dinámico, tortuoso, con acentos de luz e interés en lo ambiental. Claro que el tema manda, y dentro de las pocas licencias que entonces se podían tomar, ambos supieron trasladar al cuadro su forma de sentir. Hoy estamos acostumbrados a ver mezclas de todo tipo de códigos y un uso ecléctico de los estilos. Sin embargo, incluso en un collage -un ejercicio sobre el equilibrio- donde se conjugan imágenes de otros autores, se puede apreciar cómo se adapta la construcción del conjunto a la sensibilidad del estudiante.

Según el psicólogo de la Gestalt Rudolf Arnheim, los artistas entienden la forma como un acontecimiento ${ }^{14}$. Realmente, entre artistas, es frecuente escuchar el juicio "funciona» $\mathrm{o}$ «no funciona» aplicado a una obra en ejecución. Si funciona, el conjunto de contrastes internos - de todo tipo- se supedita adecuadamente a una unidad de sentido mayor. Se intenta alcanzar una armonía compleja que muy bien puede deberse a la particular manera de sentir su entorno el autor, una especie de emoción subyacente, que respira a través de la organización de los numerosos elementos que forman el conjunto.

$\mathrm{El}$ arte se ha relacionado con la expresión de sentimientos y emociones ${ }^{15}$. Curiosamente es un concepto que resulta fácil de asociar a la música, un arte aparentemente abstracto. Sin embargo, no siempre vemos esta asociación tan clara en la pintura. Ello se puede deber a su fuerte capacidad icónica, que permite reconocer objetos con más facilidad y enfocar la interpretación hacia el significado narrativo o contextual de lo representado. Lo que me interesa bajo este epígrafe es tratar de explicar cómo se transmiten los contenidos emotivos a través de una configuración, en nuestro caso, pictórica.

Sabemos que las diferentes artes codifican impresiones ambientales que pueden llegarnos por medio de diferentes sentidos, como la vista, en el caso de la pintura, o el oído, en el caso de la música. Pero los sentidos interactúan mediante el fenómeno de la sinestesia. Así podemos relacionar un sabor con un color. Por ejemplo, lo dulce con el rosa. $\mathrm{O}$ el sabor de un vino con la madera, que no hemos gustado sino olido.

14 «[...] los artistas, ya sean poetas, pintores o músicos, poseen una sensibilidad particularmente aguda para observar el comportamiento de lo que los rodea. Experimentan este comportamiento como una interacción de fuerzas [...]. Pero la manera que tienen de ver los artistas estas cosas como simbólicas significa que esas fuerzas responden ante los eventos dinámicos no solamente como lo que son, sino como imágenes que reflejan fuerzas internas de la mente humana [...]. Debido a que las fuerzas se sienten pero son tan abstractas como la electricidad o la gravedad, es tarea del artista tornar perceptibles los esfuerzos de la mente al verlos simbolizados en el comportamiento del entorno. El mundo de los artistas es así un bosque de símbolos». Rudolf Arnheim, El quiebre y la estructura. Veintiocho ensayos (Barcelona: Andrés Bello, 2000), 124-125.

${ }^{15}$ Existe una relación causal entre sensación, percepción y sentimiento o emoción. En el proceso que nos explica L.M. Morfaux la secuencia comienza con el excitante (físico) que provoca la excitación en el órgano receptor (fisiológico); sigue la sensación (psicológica) y la percepción, o toma de consciencia, que elabora el conocimiento perceptivo. Para la consciencia toda sensación es a la vez afectiva y representativa. Su cualidad sensible pertenece al objeto y la afectiva al sujeto. Louise Marie Morfaux, Diccionario de las ciencias humanas (Barcelona: Grijalbo, 1985), 311. 


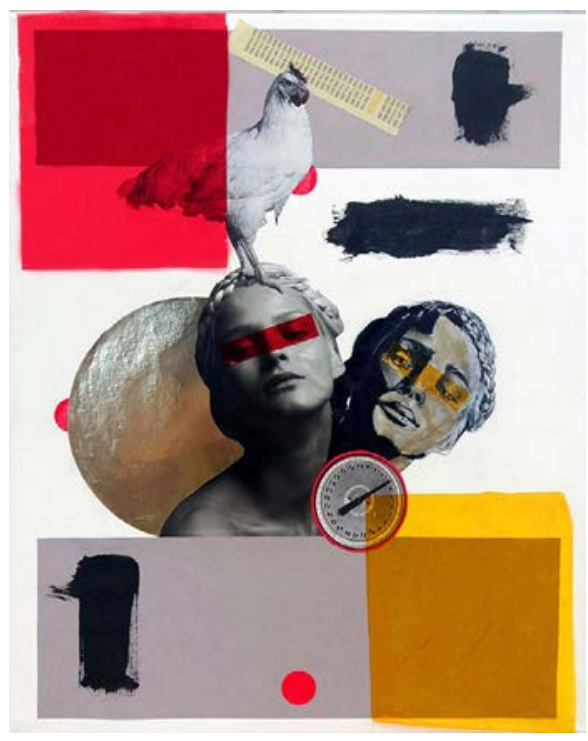

Fig. 8. Martina Armas, $41 \times 33 \mathrm{~cm}, 2017$.

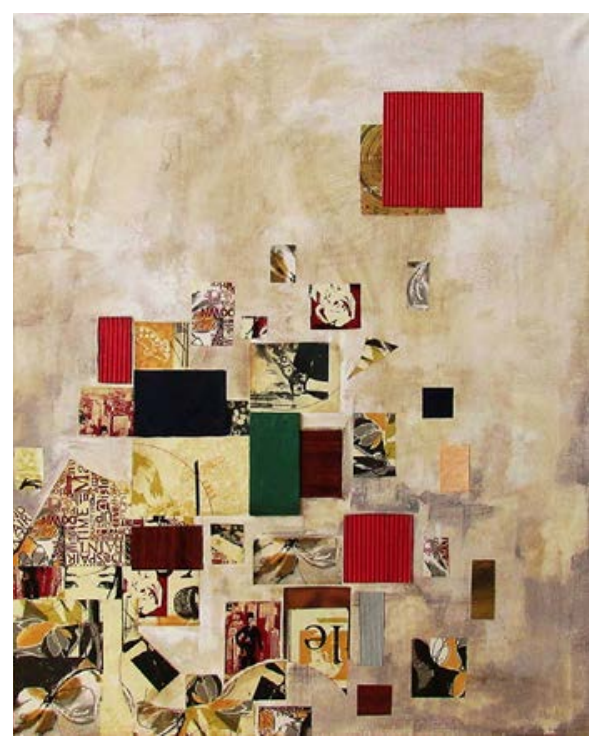

Fig. 9. Irene Morales, $61 \mathrm{~cm} \times 50 \mathrm{~cm}, 2017$.

Este aspecto en la interpretación de obras de arte ha sido ampliamente estudiado, también por los artistas. Kandinsky, en este sentido, fue un precursor al ser pintor y músico. La cosa se complica cuando empezamos a hablar de sentidos que implican una percepción de nuestro propio cuerpo como, por ejemplo, la cinestesia, la sensación de su volumen y peso moviéndose en el espacio. Estas sensaciones tendrían importancia en la danza, pero también en la escultura y la pintura ${ }^{16}$. Sin embargo, todavía estamos moviéndonos en el terreno de los sentidos que tienen nombre, porque hemos podido definirlos. ¿Qué pasa con las sensaciones difusas y «viscerales» que no sabemos definir y por lo tanto nominar? Recuerdo perfectamente el interés que me suscitó la lectura de un libro de Alexander R. Luria sobre la sensación y la percepción. En este estudio se hablaba de nuestras sensaciones interoceptivas, aquellas que nos relacionan de forma intuitiva ${ }^{17}$ con el interior de nuestro propio cuerpo y su bienestar o malestar ${ }^{18}$. Son diferentes a las sensaciones que nos informan sobre nues-

16 Sólo hay que pensar en los esfuerzos que hacen los artistas para mantener equilibrada una imagen, tanto bidimensional como tridimensional.

${ }_{17}$ Siempre he creído que gran parte de la intuición se compone de la memoria de nuestra amplia experiencia sensible.

${ }^{18}$ Luria establece una clasificación con tres tipos de sensaciones: las exteroceptivas, que nos relacionan con el exterior y comprenden lo que llamamos nuestros cinco sentidos; las propioceptivas (cinestesia), que nos informan sobre la manera en la que nuestro cuerpo se mueve por el espacio (incluye el equilibrio); las interoceptivas (cenestesia), que informan sobre el estado de los procesos inter- 
tro exterior, las exteroceptivas, al menos para el análisis, porque estas suelen limitarse a lo que entendemos como nuestros cinco sentidos: vista, oído, olfato, tacto y gusto. Me pareció que este tipo de sensaciones, las interoceptivas, nos las provocamos muchos artistas plásticos durante el proceso de configuración. Mi hipótesis en este campo ha sido que las artes nos facilitan los lenguajes necesarios para codificar, transmitir y, en ocasiones, intensificar nuestra experiencia sensible completa: la exteroceptiva, la propioceptiva (cinestesia) y la interoceptiva (visceral) ${ }^{19}$. El conjunto de todas ellas se relaciona a través de la sinestesia. Para explicarlo me pareció útil partir de la naturaleza de las emociones y su función en nuestra evolución y supervivencia.

Entiendo que nuestras emociones son, en parte, programas de reacción espontánea ante estímulos concretos. Así, el miedo ante la imagen repentina de un oso nos induce a quedarnos paralizados o a salir corriendo. Ambas reacciones tienen consecuencias físicas. El nivel de adrenalina, el cambio en la respiración, la falta de sangre en la cabeza para desplazarse a las piernas, etc., se acompaña con sensaciones interoceptivas de las que somos poco o nada conscientes en el momento de la acción. Si hubiésemos procedido a un análisis racional, pormenorizado, de las proporciones, color, textura de piel, etc., del animal antes de salir corriendo, probablemente no habríamos tenido ninguna oportunidad ante un depredador. En ocasiones es muy útil un rápido reconocimiento y una reacción automática ante un estímulo. Las reacciones emocionales y el raciocinio conviven en nuestro pensamiento, pero muchas veces cuando uno de los dos se intensifica, el otro se debilita. Obedecen a funciones diferentes y durante nuestra existencia memorizamos la contribución de ambos. En nuestro ejemplo podríamos asociar una cara excesivamente blanca, unos ojos muy abiertos y una respiración entrecortada, o ausente, con la emoción que llamamos "miedo». Las expresiones faciales, que son frecuentes en obras pictóricas y seguramente pueden transmitir la idea de miedo, han sido estudiadas con esmero por algunos artistas ${ }^{20}$. También podríamos asociar a la idea de miedo el estímulo que produce la emoción: la estructura básica de las proporciones además de las características superficiales de un oso. Algo de fácil precepción, una buena Gestalt, que permita un rápido reconocimiento en caso de peligro. Pero no estoy hablando sólo de la transmisión de la idea de una emoción, sino de la generación de la emoción misma. Para explicar esta posibilidad podemos recurrir, por ejemplo, a sensaciones provocadas por situaciones ambientales concretas que solemos compartir. Así, una puesta de sol suele ejercer cierta fascinación sobre muchas personas. Esto parece deberse a que, en

nos del organismo y hacen llegar al cerebro estímulos procedentes de aparatos viscerales. Estas últimas son aquellas de las que tenemos menos conciencia, por difusas, y tienen afinidad con los estados emocionales. Alexander, R. Luria, Sensación y percepción (Barcelona: Martínez Roca, 1984), 18-26.

19 Sabina Gau Pudelko, El proceso de creación artística. Diálogo con lo inefable (Santa Cruz de Tenerife: Universidad de La Laguna, 2003).

${ }^{20}$ Miquel Quilez Bach le ha dedicado varios proyectos. Miquel Quilez Bach, I Jornadas Internacionales: El rostro humano, identidad y parecido [actas] (Barcelona: Facultat de Belles Arts, 2014), 41. http://www.ub.edu/dyn/cms/galeries/documents/noticies/programa_jornadas_el_rostro_ humano.pdf (consultada el 16 de junio de 2018). 
el pasado, la puesta de sol significaba un cambio brusco en las condiciones ambientales. Se pasaba en poco tiempo de la luz a la oscuridad y había que prepararse. Prestar atención. Después de muchas generaciones, incluso disponiendo de luz eléctrica, a través de nuestra memoria filogenética muchos seguimos sintiendo esa fascinación que nos orienta a mirar cuando se pone el sol. De la misma manera, las condiciones características de la luz, poco antes de una tormenta, pueden crear angustia o precaución. Si un pintor traslada a un lienzo un sistema de tonos lumínicos en el que se quiebra en varias ocasiones de forma brusca la degradación normal de la intensidad de la luz, puede provocar esa angustia incluso sin necesidad de reproducir una escena reconocible como un paisaje. También una distribución ilógica de la luz -como un cielo oscuro sobre una tierra iluminada- podría crear inquietud inconsciente. Estamos hablando, entonces, de sistemas configuracionales que podríamos denominar abstractos pero que de manera intuitiva pueden provocar sensaciones concretas, aunque difusas. Los pintores las pueden buscar de forma inconsciente pero deliberada en el ejercicio de su práctica plástica, organizando de manera experimental los recursos de su lenguaje, alerta ante la resonancia emocional de su interacción. Muchas veces los anima una intención lúdica o, también, la ambición de provocarse una serie de sensaciones que anhelan intensificar a través del diálogo íntimo que establecen con su imagen. Con la experiencia, el pintor aprende a emplear con más propiedad sus recursos para canalizar una experiencia emotiva. Hay que añadir, sin embargo, que uno no llega a provocarse una reacción sensible mediante la aplicación de rasgos pertinentes, o sumando diferentes sistemas configuracionales, después de tomar una serie de decisiones racionales de selección y combinación. Normalmente se avanza poco a poco, de manera intuitiva, probando, construyendo y destruyendo con una atención abierta a las propias reacciones. Creo que esto se debe a que los estímulos aplicables son innumerables y sus combinaciones infinitas. No se limitan, ni mucho menos, a casos que podemos analizar racionalmente, como los ejemplos citados más arriba. $\mathrm{Si}$ fuera así de fácil probablemente se habría dejado de pintar.

\section{JUGAR CON EL LENGUAJE}

Sabemos que el lenguaje es el instrumento del pensamiento. Sin lenguaje no se puede pensar. Se pinta como se piensa. Lenguaje y pensamiento son interdependientes. Cuando se pinta entran en acción tanto el pensamiento racional como el pensamiento visual. En ocasiones entran en conflicto y el peso de cada uno de ellos define muchas veces el código pictórico y la elección del proceso creativo. La pintura se basa, en gran medida, en el lenguaje visual. Según Hans Daucher el pensamiento que lo sustenta elabora las imágenes por comparación y discurre en niveles superpuestos, mientras el pensamiento racional elabora su lenguaje a partir de conceptos vinculados en el juicio y discurre de forma lineal y causal ${ }^{21}$. El lenguaje pic-

${ }^{21}$ Hans Daucher, Visión artística, visión racionalizada (Barcelona: Gustavo Gili, 1978), 11. 
tórico se construye, desde las pinturas rupestres, con materias coloreadas dispuestas sobre un soporte, que habitualmente tiene unos límites que decide el artista. Se combinan de tal manera que sus contrastes hacen perceptibles unas formas positivas que tienen un significado para el autor, pasando el resto de la superficie a convertirse en formas negativas o "ruido». Gran parte de su potencial expresivo se atribuye a la interacción del color.

En mis clases solemos trabajar la pintura de manera tradicional, con soporte material y pigmentos aglutinados con aceite o resina acrílica. Pero podemos ampliar el concepto aceptando la idea que Omar Pascual facilitó a Lucía Vázquez Carpio, en una entrevista para su tesis doctoral. Preguntado por las condiciones que convertían una imagen actual en pintura, este crítico contestó que podía considerarse pintura la obra pensada y ejecutada desde el conocimiento de lo pictórico, aunque se tratara de un dibujo, una fotografía o una mancha de luz en el espacio ${ }^{22}$. Podemos convenir, de nuevo, en que los contenidos de una imagen pictórica se pueden comunicar gracias a la codificación de un lenguaje que se ocupa de lo visual. Por supuesto no es lo mismo la impresión que produce ver una obra directamente en un museo que su reproducción en la red, pero hay que reconocer que el efecto puede ser semejante. Tal vez por ello visitemos menos los museos y pasemos más tiempo en la web, mirando arte. Bien es verdad que nos perdemos las cualidades del material y la experiencia de los grandes formatos, en ocasiones envolventes, por no mencionar que las reproducciones se manipulan para ser más efectistas. Sin embargo, la imagen visual se percibe bastante bien siempre que puedan apreciarse simultáneamente todos sus aspectos formales en relación con el conjunto. Por eso es tan lamentable que veamos reproducciones de imágenes incompletas o que un reportaje televisivo sobre pintura comience mostrando detalles de un cuadro antes de llegar a mostrarlo en su totalidad.

Se considera que los humanos se rigen sobre todo por su sentido de la vista y puede ser interesante imaginar que nuestros productos culturales serían muy diferentes si nuestro sentido prioritario fuese el olfato. Así, Frank Wilczek piensa que una especie así, de criaturas sociales inteligentes, poseería otra clase de entendimiento del mundo físico y «tendrían grandes juegos de química, una cocina elaborada, afrodisíacos y, al modo de Proust, memorias evocadoras. Pero quizá no tanta geometría proyectiva ni astronomía [...]. Pero el problema 'inverso' de reconstruir, a partir de los olores, las moléculas y sus leyes, y al final la física que conocemos, parece desesperadamente difícil $»^{23}$. Es probable que la codificación de las condiciones que nos rodean sea más fácil a través de impresiones visuales. Habría que añadir, también, que el sentido de la vista ha sido tan útil porque nos informa sobre nuestro entorno inmediato y lejano. El oído también tiene esa cualidad, si bien en menor medida,

22 Leticia Azahara Vázquez Carpio, Revisión de la idea de pintura desde una perspectiva contemporánea: Desdibujando los limites (Granada: Universidad de Granada, 2016), 214. http://digibug. ugr.es/handle/10481/43255.

${ }^{23}$ Frank Wilzek, El mundo como obra de arte. En busca del diseño profundo de la naturaleza (Barcelona: Crítica, 2015), 23. 
pero nuestros sentidos exteroceptivos del olfato, tacto y gusto requieren proximidad al objeto percibido.

El caso es que somos criaturas visuales y es normal que elaboremos productos culturales mediante el tipo de sensaciones que percibimos organizados por medio de ese sentido. Entiendo la definición de producto cultural en un sentido amplio. La definición de cultura que más me ha interesado es la que citó un antropólogo cuyo nombre no he logrado recuperar, pero que rezaba así: «La cultura es la codificación de todas las soluciones que ha ideado el hombre en su adaptación al presente eterno $»^{24}$. Sabemos que el ser humano codifica aquello que quiere conservar. Es información a transmitir. Lo mismo se puede tratar de una aportación de las matemáticas, el arte o la filosofía que referirse a algún deporte, cuyas reglas tal vez simbolizan una guerra; o quizás un tipo de baile folclórico, cuyos movimientos recuerdan alguna fiesta de agradecimiento por la cosecha. El caso es que se han ideado mil códigos para transmitir gran diversidad de contenidos mentales, tanto analógicos, por imitación -dibujos-, como digitales -notas musicales-, para que esos contenidos puedan sobrevivir en las generaciones siguientes. Para ilustrar esa idea amplia de cultura, y el concepto de lenguaje, a veces me ha parecido interesante relacionar las diferentes inteligencias descritas por Howard Gardner-en su teoría de las inteligencias múltiples- con los diversos lenguajes que sirven a su comunicación.

La pintura es un producto cultural, por lo que vamos a admitir que está codificado y tiene contenidos que transmitir. Por todo ello y en virtud de un acuerdo más o menos extendido, hemos considerado a la pintura también un lenguaje. No en el sentido ortodoxo de lenguaje que requiere una definición clara de los elementos mínimos y reglas sintácticas perfectamente definidas, en diferentes niveles de articulación. No existe el mismo acuerdo sobre su funcionamiento como podría suponerse en el lenguaje verbal, que puede descomponerse en letras, palabras, frases, párrafos, textos y contextos y que, además, cuenta con unas reglas gramaticales que velan por su buen uso. Pero podríamos considerar la pintura un sistema de signos visuales. Umberto Eco entendía un signo como todo lo que en virtud de una convención compartida estaba en lugar de otra $\operatorname{cosa}^{25}$, es decir, algo que significa algo para un grupo que comparte un código. Edward $\mathrm{O}$. Wilson también insiste en que el productor y el intérprete deben compartir un tipo de conocimiento al decir que «el arte es el medio por el que personas de cognición similar se comunican con los demás para transmitir sensaciones $\aleph^{26}$.

Ha sido problemático, sin embargo, decidir cómo podrían ser estos signos mínimos que se interrelacionan en el sistema que sostiene un cuadro. Se han hecho clasificaciones con aspectos formales básicos como punto, línea, plano, tono, color,

${ }^{24}$ Jesús Mosterín también tiene una definición amplia de la cultura; la entiende como la información transmitida por aprendizaje social entre animales de la misma especie. https:// es.wikipedia.org/wiki/Antropolog\%C3\%ADa_cultural (consulta el 07/06/2018).

${ }^{25}$ Umberto Eco, Tratado de semiótica general (Barcelona: Lumen, 1985), 46.

${ }^{26}$ Edward O. Wilson, Consilience. La unidad del conocimiento (Barcelona: Galaxia Gutenberg/Círculo de lectores, 1999), 10. 
textura, etc., pero ninguno de estos elementos suele tener un significado en sí mismo. Sin embargo, su interrelación es capaz de transmitir significados racionales y sensibles. El análisis formal de los aspectos estructurales en clases de composición, por ejemplo, puede arrojar algo de luz sobre la influencia de los aspectos sintácticos en la cohesión del conjunto o en la transmisión de algunas sensaciones. Sin embargo, es muy insuficiente para comprender toda la amplitud de posibilidades que ofrecen las imágenes visuales. Esas se van comprendiendo con el ejercicio de la pintura. A pintar se aprende pintando. Entonces, con el hacer se va comprendiendo con relativa facilidad cómo nos afectan diferentes combinaciones de los recursos formales, a través de la confrontación con ellas, cuando se producen en el lienzo, por voluntad o por azar.

Pienso que los signos mínimos, es decir, las unidades mínimas de significado, podrían ser esas estructuras abstraídas de condiciones ambientales concretas que nos han afectado y guardamos en nuestra memoria. Las puede representar tanto una línea como una mancha o un icono. El problema es que en una obra pictórica se superponen simultáneamente y en combinaciones interminables. Un pequeño cambio en la estructura del conjunto, o cualquier otro aspecto formal como las relaciones cromáticas, tonales o texturales, puede acabar con la impresión que el conjunto nos imponía poco antes. Siempre se puede perder en un momento lo que ha costado días o semanas construir. Incluso la iluminación inadecuada de una sala de exposiciones puede «matar» un cuadro. Recuerdo un vídeo realizado por Corinna Belz, donde se ve al conocido pintor Gerhard Richter pintando ${ }^{27}$. Richter quizás sea el pintor que más ha experimentado con diferentes códigos pictóricos. Se reinventa constantemente. Pero incluso un pintor de su categoría y experiencia le dice a la entrevistadora: "Hoy no funciona», cuando sus esfuerzos no obtienen el resultado que espera. También se le observa, volviendo a su estudio, mirar un cuadro en ejecución, al que ha dedicado mucho tiempo y lo encuentra de repente «horrible». El riesgo de un cambio en la apreciación es parte de la trayectoria venturosa del oficio y sirve a la búsqueda de conocimiento a través de este medio. Pero las satisfacciones también son grandes cuando una obra llega a un término que sorprende o agrada al autor.

En el contexto de una clase de pintura podemos observar cómo algunos alumnos se permiten dudar y mantener un pensamiento divergente ante la combinación inesperada de recursos formales. La intención es comprender sus efectos sobre la apreciación sensible y así, tal vez, emplearla en un futuro. Nuestra alumna Irene Morales, por ejemplo, se encontró confrontando contrastes difíciles de armonizar, al pintar su trabajo de mímesis sobre un cuadro ya pintado por otro alumno del curso anterior. El motivo inicial de su proceder era el ahorro que suponía reciclar un soporte. La superposición parcial de una imagen en ejecución sobre otra anterior le proporcionó la visión simultánea de diferentes planteamientos, como podrían ser

${ }^{27}$ Gerhard Richter-Painting. Dirigida por Corinna Belz. Westdeutscher Rundfunk (WDR) / Mitteldeutscher Rundfunk (MDR) / ARTE / Zero One Film / Terz Film. 2011. 


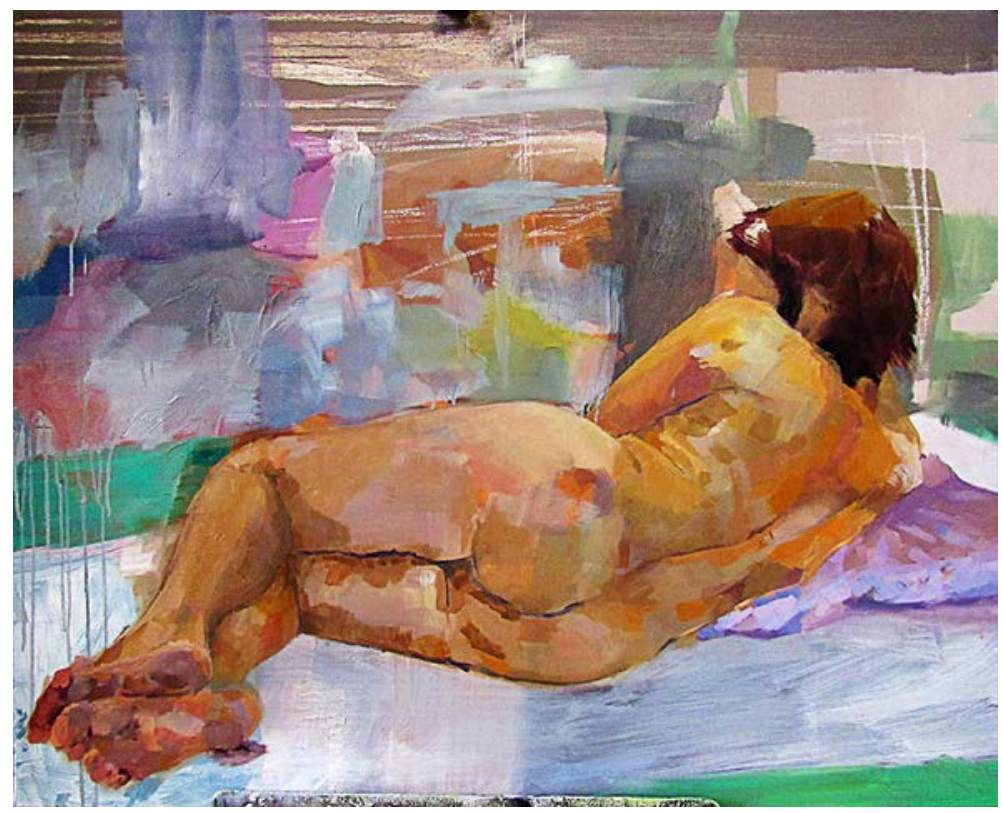

Fig. 10. Irene Morales Almeda, Sin título, óleo sobre lienzo, $81 \times 100 \mathrm{~cm}, 2018$.

las variadas técnicas de aplicación de la pintura, la representación plana y escenográfica del espacio o la combinación de gamas cromáticas pertenecientes a diferentes sensibilidades. Estas contradicciones visuales la animaron a explorar las posibilidades que surgen al conjugar aspectos formales que, en su nivel de formación, desconocía.

Suele ocurrir, en un proceso de creación pictórica, que el autor provoque efectos azarosos de resultado un tanto imprevisible, para luego ejercitarse en la estimulante tarea de intentar armonizarlos. Sin embargo, cuando se ha llegado a profundizar en el conocimiento de un lenguaje concreto este puede dejar de interesar porque se vuelve previsible. Entonces muchos artistas realizan cambios deliberados, por ejemplo, en el planteamiento, el tema o el material. En ocasiones, los artistas restringen sus recursos para centrarse en algún aspecto concreto. Podemos recordar a Josef Albers limitando las combinaciones formales a cuadrados superpuestos para centrarse en las más sutiles combinaciones cromáticas. También podemos mencionar la confrontación de algunos artistas con códigos de representación desconocidos. Vemos el impacto de la escultura africana en las Señoritas de Avignon de Picasso, o del arte infantil y de enfermos mentales en el expresionismo de Asger Jorn o Jean Dubuffet. Estos códigos cobraron tal interés en estos artistas que decidieron explorarlos a través de su propia pintura.

Es fácil pensar que los artistas que conocen bien su lenguaje juegan con sus recursos para seguir explorando sus posibilidades porque la manipulación de los 
recursos formales y su sintaxis conlleva un cambio en el contenido ${ }^{28}$. L. Vigotski entendió que las buenas obras de arte podían provocar cierta complejidad emocional y cognitiva al presentar aspectos afectivos opuestos: "Dos planos contradictorios, que se desarrollan dialécticamente y llevan a una síntesis o resolución superior de los elementos antitéticos ${ }^{29}$. El poeta J.W. Goethe ya decía que el arte consistía en crear y reunificar contrastes ${ }^{30}$. Esta estrategia que consiste en desautomatizar el lenguaje requiere una notable tolerancia a la ambigüedad. Los artistas suelen construir a través de sus recursos sintácticos contradicciones internas en un conjunto. Estas se supeditan a un orden superior lo suficientemente fuerte para soportarlos. Se trata de negar el signo evidente, la comprensión primera y seguir indagando, sondeando los límites, a la vez que se mantiene abierta la atención a sus efectos. Tal vez se trata, en esencia, de demorarse más de lo necesario entre la sensación y la percepción, negando en parte la última para entender mejor la primera. El juego con el lenguaje involucra la psique del artista, que le guía hacia armonías cada vez más complejas e imprevisibles, profundizando en el pensamiento visual. Le acompaña la excitación propia del descubrimiento dentro de los límites de su lenguaje, en el terreno de lo posible y en el campo de la ficción.

\section{CONCLUSIONES}

Las obras pictóricas son capaces de comunicar diferentes tipos de contenidos y todos ellos ya se vislumbran, en diferentes grados de madurez, en los estudiantes de Bellas Artes. En este artículo se esbozan cinco tipos de contenidos que pueden motivar a un adulto a elaborar imágenes pictóricas. La profundización en cualquiera de ellos puede condicionar la calidad artística. Sin embargo, no son excluyentes entre sí y la confluencia de más de uno de estos contenidos, en la misma imagen, puede mantener o aumentar su interés, tanto en el autor como en el receptor.

La pintura invita, en la ficción, a experimentar con enfoques temáticos nuevos; con la apertura a sensaciones matizadas y contrapuestas; con la experiencia de dejarse afectar por los cambios, probables e improbables, en el uso de su lenguaje. De tal manera que en el ejercicio de pintar se van ampliando los recursos para seguir indagando en la comprensión de las relaciones formales y su efecto. Armonizar significa unificar lo diverso. Cuadros aparentemente sencillos pueden contar con numerosas contradicciones internas, construyendo una complejidad creciente cuya explo-

${ }^{28}$ En palabras de Picasso: «Cuando se empieza un cuadro, a menudo se realizan algunos hermosos descubrimientos. Es preciso ponerse en guardia contra ellos. Destrúyase la cosa, rehágasela varias veces. Cada vez que destruye un bello descubrimiento, el artista no lo suprime realmente, y más bien lo transforma, lo condensa, le confiere mayor sustancialidad. Y el producto final es el resultado de los hallazgos que fueron dejados de lado. De lo contrario, uno se convierte en su propio connaisseur. Por mi parte, jamás me vendo nada». Herbert Read, Carta a un joven pintor (Buenos Aires: Siglo XX, 1985), 21.

29 Darío D. Páez y J.A. Adrián, Arte, lenguaje y emoción: La función de la experiencia estética desde una perspectiva vigotskiana (Madrid: Fundamentos, 1993), 87.

${ }^{30}$ Hans Daucher, op. cit., 58. 
ración puede ser motivo suficiente para no abandonar el taller. A mi juicio, las artes tienen la capacidad de codificar las armonías más sofisticadas que puede producir la sensibilidad humana. Creo que es una de las razones por las que las buenas obras de arte no envejecen. La complejidad que pueden ofrecer al lector permiten mantener el interés en ellas cuando ya han pasado de moda.

ReCIBIDO: noviembre de 2018; ACEPTADO: noviembre de 2019 


\section{REFERENCIAS BIBLIOGRÁFICAS}

Alameda, Soledad, «Antonio López, el que sueña con la luz», El Pais Semanal 104, 14 de febrero, 1992. Arnheim, Rudolf. 2000. El quiebre y la estructura. Veintiocho ensayos. Barcelona: Andrés Bello.

Blanco, Pilar y Gau, Sabina. 1996. Fundamentos de la composición pictórica. Santa Cruz de Tenerife: Consejería de Educación, Cultura y Deportes, Dirección General de Universidades e Investigación, Gobierno de Canarias.

Daucher, Hans. 1978. Visión artística, visión racionalizada. Barcelona: Gustavo Gili.

Eco, Umberto. 1985. Tratado de semiótica general. Barcelona: Lumen.

Eid, Klaus, Langer, Michael y Ruprecht, Hakon. 1980. Grundlagen des Kunstunterrichts. Paderborn: Verlag Ferdinand Schöningh.

GAU, Sabina. 2003. El proceso de creación artística. Diálogo con lo inefable. La Laguna: Universidad de La Laguna.

GuILFORD, J.P. 1968. Intelligence, creativity and their educational implications. San Diego, California: Robert R. Knapp.

Krieger, Verena. 2007. Was ist ein Künstler? Colonia: Deubner Verlag.

Luria, Alexander, R. 1984. Sensación y percepción. Barcelona: Martínez Roca.

Martín SÁnchez, Miguel Ángel. 1991. Miguel, el arcángel de Dios en Canarias. Aspectos socioculturales y artísticos. Santa Cruz de Tenerife: Cabildo Insular de Tenerife.

Morfaux, Louise Marie. 1985. Diccionario de las ciencias humanas. Barcelona: Grijalbo.

Quilez I BACH, Miquel. 2014. En actas de I Jornadas Internacionales El rostro humano, identidady parecido. Barcelona: Facultat de Belles Arts.

Páez, Darío D. y Adrián, J.A. 1993. Arte, lenguaje y emoción: La función de la experiencia estética desde una perspectiva vigotskiana. Madrid: Fundamentos.

Pinker, Steven. 2000. Cómo funciona la mente. Barcelona: Destino.

READ, Herbert. 1985. Carta a un joven pintor. Buenos Aires: Siglo XX.

Regel, Günter. 1986. Medium bildende Kunst: bildnerischer Prozess. Prozess und Sprache der Formen und Farben. Ost-Berlin: Henschelverlag.

Tolosa, José Luis. 2005. Mirar haciendo, hacer creando: Práctica y teoría de la pintura. Barcelona: Tursen/Hermann Blume.

VÁzquez Carpio, Leticia Azahara. 2016. Revisión de la idea de pintura desde una perspectiva contemporánea: Desdibujando los limites (tesis doctoral). Granada: Universidad de Granada.

WilczeK, Frank. 2015. El mundo como obra de arte. En busca del diseño profundo de la naturaleza. Barcelona: Crítica.

Wilson, O. Edward. 1999. Consilience. La unidad del conocimiento. Barcelona: Galaxia Gutenberg/ Círculo de lectores. 